\title{
Article \\ Fast Falling Weight Deflectometer Method for Condition Assessment of RC Bridges
}

\author{
Mauro Coni (D), Fausto Mistretta (D), Flavio Stochino (D), James Rombi $\mathbb{D}$, Mauro Sassu (D) and Mario Lucio Puppio *(D) \\ Department of Civil Environmental Engineering and Architecture, University of Cagliari, 09124 Cagliari, Italy; \\ mconi@unica.it (M.C.); fmistret@unica.it (F.M.); fstochino@unica.it (F.S.); james.14@tiscali.it (J.R.); \\ msassu@unica.it (M.S.) \\ * Correspondence: mariol.puppio@unica.it; Tel.: +39-070-6755408
}

check for updates

Citation: Coni, M.; Mistretta, F.; Stochino, F.; Rombi, J.; Sassu, M.; Puppio, M.L. Fast Falling Weight Deflectometer Method for Condition Assessment of RC Bridges. Appl. Sci. 2021, 11, 1743. https://doi.org/ 10.3390/app11041743

Academic Editor: Raffaele Zinno

Received: 19 January 2021

Accepted: 10 February 2021

Published: 16 February 2021

Publisher's Note: MDPI stays neutral with regard to jurisdictional claims in published maps and institutional affiliations.

Copyright: (c) 2021 by the authors. Licensee MDPI, Basel, Switzerland. This article is an open access article distributed under the terms and conditions of the Creative Commons Attribution (CC BY) license (https:/ / creativecommons.org/licenses/by/ $4.0 /)$.
Featured Application: Non-destructive tests to have a rapid condition assessment of bridges, using the Fast-Falling Weight Deflectometer.

Abstract: In this paper, the use of Fast Falling Weight Deflectometer (Fast-FWD) is analyzed as a non-destructive and quick test procedure to evaluate the efficiency of short-span bridges. The Fast-FWD is an instrument that can produce a broadband dynamic force up to an impact value of $120 \mathrm{KN}$ : The impact is constant and replicable, providing accurate action measures of bridge stiffness in a truly short period (30 ms). In this paper, a single-span reinforced concrete bridge is investigated, using the Fast-FWD. The considered bridge, approximately $12.0 \mathrm{~m}$ long and $15.5 \mathrm{~m}$ wide, was in critical condition. The bridge is in a suburban principal road near to the City of Cagliari in Sardinia (Italy), with an Annual Average Daily Traffic of 13,500 vehicles/day, and was suddenly closed, creating serious problems for urban mobility. In these conditions, the investigation through other standard techniques is time-consuming and labor intensive. For this reason, it is important to introduce methods that can be rapid, accurate and cost-efficient. In this paper, bridge stiffness values obtained during the in situ experimental campaign were compared with finite element models values. The Fast-FWD has the potential to provide engineering information that can help us to better understand bridge condition, in a rapid and cost-effective procedure.

Keywords: Fast Falling Weight Deflectometer (Fast-FWD); bridge health monitoring; structural response; non-destructive test; finite element modelling

\section{Introduction}

Health monitoring of civil infrastructure is nowadays a pivotal point in civil engineering and in the maintenance program of the infrastructures. Nowadays the collapse of bridges or similar artwork, also induced by extreme climatic events [1,2], plays a strategic role even in the emergency plan [2,3]. The decay due to aging, deterioration of the materials and lack of maintenance can induce a sensible modification of the static and dynamic response of the infrastructure [4,5].

A significant element of vulnerability of this kind of infrastructure is the hydraulic one [1,6]. Recent collapses [7] highlighted a significant role of rainstorms in the safety evaluation of reduced-span bridges.

Several strategies are available to determine the structural conditions and mechanical performances of bridges and viaducts. An interesting review of a method of damage assessment is presented in References [8-11], in which the possibility to derive a structural condition index throughout the displacement and strain monitoring is investigated. At this purpose, the most effective approach is to perform a continuum investigation of the infrastructure during its life span [12], from the construction through the life cycle. Given that this is not possible for a large part of the existing infrastructures, other strategies should be developed. 
In References [13,14], a fast method to relieve the geometry and furnish a safety evaluation of the infrastructure is proposed. Ongoing research is focused on the identification of the mechanical property of concrete throughout ultrasonic method and combined method [15-19]. Although the traditional non-destructive methods had a significant enhancement [20] in the last period, a benchmark Finite Element (FE) model for the evaluation of the structural vulnerability is often necessary also improved with several tuning methods [21].

Furthermore, full-scale tests are performed to determine bridge stiffness that derives from the stiffness of each structural component [22]. Tests consist essentially of nondestructive static and dynamic methodologies. Stiffness can be obtained by measuring strains and displacements resulting from static load tests. In this field, the research in dynamic [23] and earthquake engineering [24] furnishes interesting insight.

Another branch of investigation is based on the modal identification of the structural response and the comparison of this with numerical results from FE models [25,26]. The natural frequency of a bridge can be measured with the detection of the acceleration induced by vibrating mass or impacts. The Experimental Modal Analysis (EMA) [27] is an interesting way to investigate structural health [27]. This method encounters the principal limits in the interpretation of the dynamic response with an FE. In addition, the environmental actions, as well as temperature, wind and environmental vibration, affect the dynamic response in a sensible way [28]. Each technique is time-consuming in terms of setting the instrumentation and performing the tests and back calculation of the results. In many cases, tests must be performed by closing the bridge to traffic, causing severe disruption to the daily flow of traffic. For these reasons, new strategies should be introduced that are more rapid, accurate and cost-efficient [29,30].

A crucial issue for stakeholders is monitoring infrastructures in a more accurate and rapid way, to achieve results in short time and address efficiently the economic resources for maintenance and/or rehabilitation works. In Italy, there are more than 1.5 million bridges (from short to large span), and approximatively only $4 \%$ of these are monitored.

After the Morandi bridge disaster in Genova (Italy) on 14 August 2018, a dramatic collapse of a $210 \mathrm{~m}$ central section of the viaduct in which 43 people died, a vast public debate has focused on the needs of the bridges maintenance in Italy and Europe. In May 2020, the Italian Higher Council of Public Works of the Ministry of Infrastructure and Transport approved the "Guidelines for the classification and management of risk, the assessment of safety and the monitoring of existing bridges". The importance to develop efficient, low-cost, replicable, accurate and low time-consuming tools to monitoring bridges is clear.

The original Falling Weight Deflectometer (FWD) allows us to perform one test in 5 min, while traditional impulsive methods need hours or days. The Fast-FWD is five times faster per drop than the original one. The original hydraulic load lifting system has been replaced by an electric motor. Its main field of application is in monitoring of pavement engineering, capable of performing tests on flexible (asphalt), rigid (concrete) and semi-rigid pavements (asphalt and concrete). The Fast-FWD is mounted on a trailer and towed by a vehicle especially instrumented (Figure 1): The operator can control the testing unit with a laptop computer. A test can be performed in less than one minute once the testing position has been reached. It is possible to reply to a high number of tests in a limited time, by applying impulsive loads on the structure surface and recording the deflections at different distances from the load application.

The use of Fast-FWD to evaluate stiffness values of pavement structure [31] was introduced in the late 1970s. Its application gradually spread in the middle of the 1990s, becoming more used, especially in the USA. [32,33]. Some case studies are available in the literature: in 1996, tests regarded two bridges in Virginia (USA) measuring deflections on bridge decks [33]; in 2001, it was used to measure natural frequency of a bridge and compared it with prior test results, to identify damage [34]. Moreover, it has been suggested to consider the use of a large impulse source, such as the FWD, for locating natural 
frequencies during preliminary vibrating testing of bridges [35]. In a recent study, the feasibility was explored of FWD as an impact force on two bridges and compared with an impact hammer test [36].

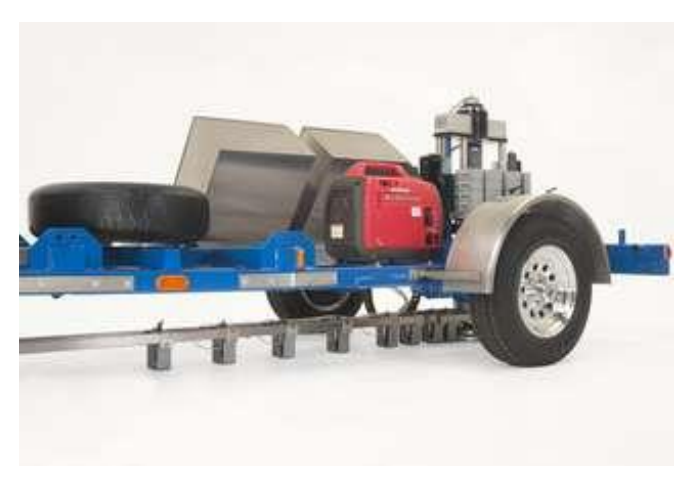

(a)

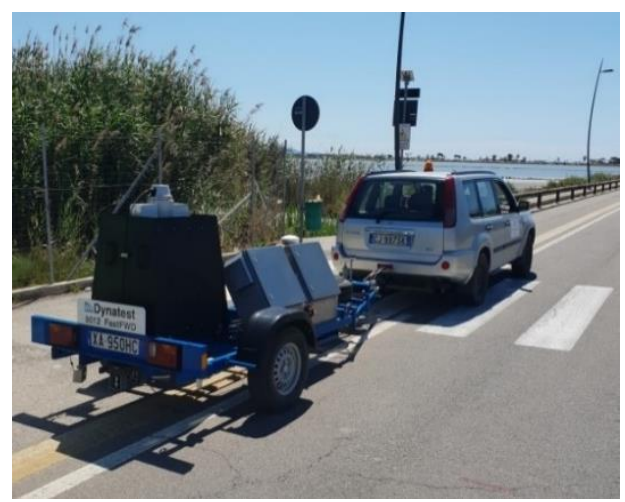

(b)

Figure 1. (a) Fast Falling Weight Deflectometer (Fast-FWD) with the main elements: falling mass and geophones of measure bar [37] and (b) on trailer towed by vehicle ready for testing.

The application of a Fast Falling Weight Deflectometer to determine the modal shape of existing bridges is described in Reference [38], in which two case studies are considered: a Parker Pony Truss (Hartbarger Bridge) and a modern concrete deck on rolled steel beam (Baptist Ford Bridge). The modal shape is analyzed through an accelerometer. It is highlighted how the FWD can create proper impact forces that are useful for screening bridges and detecting performance and conditions.

The aim of the research is to evaluate whether Fast-FWD can furnish bridge stiffness values, to help engineers to understand bridge performance and conditions, detecting also possible deteriorations replacing tests over time.

This paper presents a case study in which the Fast-FWD used as a controlled excitation device was analyzed, performing impact dynamic testing on a single span-bridge approximately $12.0 \mathrm{~m}$ long and $15.5 \mathrm{~m}$ wide. It overpassed the Perdalonga canal (Figure 2), located in the city of Quartu Sant'Elena (Sardinia, Italy), along Colombo Avenue.

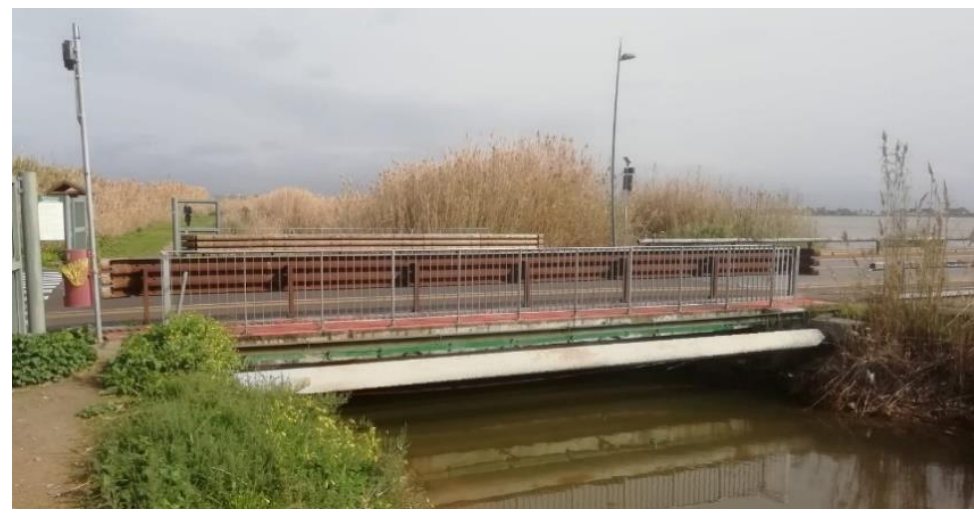

Figure 2. Bridge on Perdalonga canal Quartu Sant'Elena (Sardinia, Italy).

Forty-eight tests were performed in less than one hour, on the bridge deck, abutment and also on the approach paved embankment. The results obtained were analyzed throughout an FE analysis in ANSYS (R18.1) environment. 


\section{Methods of Analysis}

\subsection{Fast Falling Weight Deflectometer (Fast-FWD)}

The deflections induced by Fast-FWD were obtained by a series of impulses from a repeated falling load. The deflectometric data registered by Fast-FWD data acquisition system were processed to assess deflection basin parameters and pavement layers stiffness through ELMOD 6 software [39] developed by Dynatest [40]. The load is pushed by a circular steel plate of diameter $300 \mathrm{~mm}$. The plate is segmented in four angular sectors, to better match the shape of the tires footprint. Twelve velocity transducers (geophones) are along a line radiating out from the load plate to a max distance of 2100 (Figure 3). The geophone numbers 11 and 12 were placed in approximately symmetric position with respect to the geophone numbers 2 and 3, to check the deflection basin nearest to the impact point. The impulse was given in correspondence with the measurement axis, aligned with the geophones zero. The measurement axis was moved along all the bridge deck during the experimental campaign. In this experimental campaign, the geophone bar was moved alongside the road axis; so, for each drop, longitudinal deflection is measured.

The weight and the drop height of the falling mass can be modified: The weighting mass range is $50-350 \mathrm{~kg}$, while the drop height is from 50 to $390 \mathrm{~mm}$, so the impulse load can range from 40 to $120 \mathrm{kN}$, acting on mass and drop height. The duration of the impulse load ranges from 25 to $30 \mathrm{~ms}$. For each drop, the system samples the load and measures the time history of the deflection in a period of $60 \mathrm{~ms}$. The load is applied by a falling mass with a fixed height drop and is verified with a Dynamometer. The kind of pavement can influence the local pressure, but the axial load is fixed.

The standard test comprises three repeated drops with the same load or through progressive impulse with growing stress. It is useful to perform the test with three different vertical stresses, to investigate if the response of the system is linear with respect to the intensity of the impulse.

Figure 3 shows a typical deflection basin measured by the geophones after the impulsive load. The deflection profile is influenced by the properties of the pavement layers, as well of the magnitude and frequency of the loading [31]. The largest deflection is in correspondence of the loading point, measured by the $\mathrm{D}_{1}$ and $\mathrm{D}_{11}$ geophones. The amplitude and the shape of the basin contain information about the stiffness of the layers of the pavement; the time history of the deflection contains information about the dynamic properties of the underlying layers.

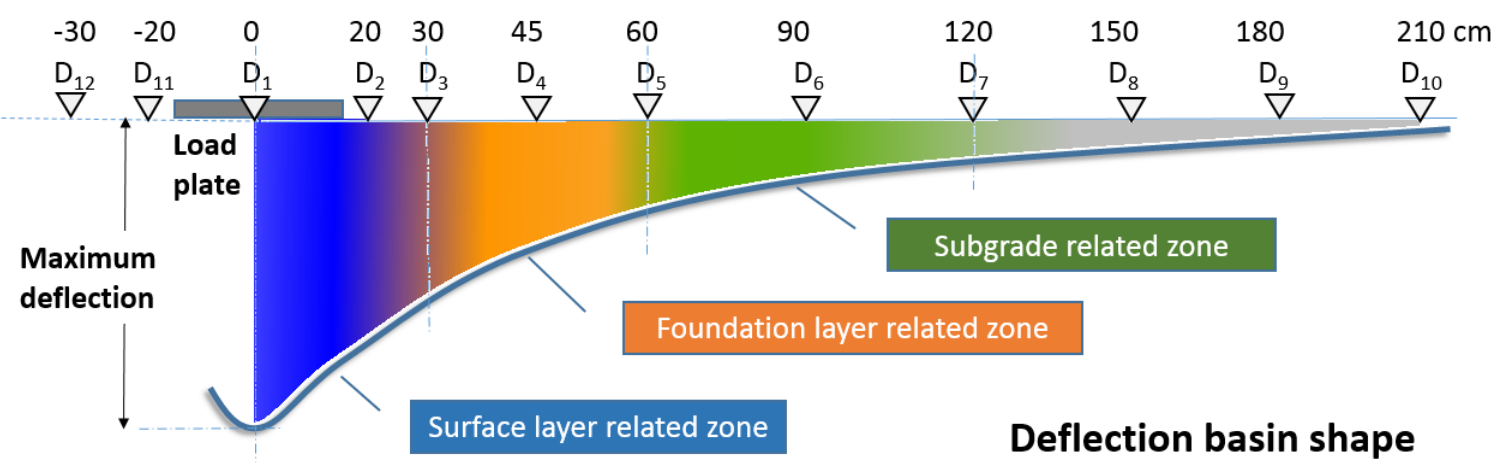

Figure 3. Basin shape profile, number and position of the Geophone.

From this data, some synthetic indicators can be drawn. Conventional stiffness values were obtained by dividing the applied load with the displacement obtained measured by the axial geophone $D_{0}$.

$$
K=\frac{F}{D_{0}}
$$

where $F$-impulsive load and $D_{0}$-maximum deflection measured at the center of the plate. 
In addition, the analysis of the basin shape furnishes some indicators called "Basin Indexes". These are defined in References [41,42]. The more relevant ones in the analysis of the concrete deck are defined in Equations (2)-(6) and described below. The radius of curvature (RC) defines the average radius of curvature of the deflection basin related to the radius of the load plate. The Surface Condition Index (SCI), Base Distress Index (BDI), and Deep Condition Index (DCI) are defined as the difference of the deflection at different distance from the load points. Rectangular Area (RA) indicator is a synthetic that considers the summation of all the displacements related to $D_{1}$.

$$
\begin{gathered}
R C=\frac{R^{2}}{2\left(D_{0}-D_{200}\right)} \\
S C I=D_{0}-D_{300} \\
B D I=D_{0}-D_{600} \\
D C I=D_{900}-D_{2100} \\
R A=\frac{\sum_{n=1}^{N} D_{i}}{D_{1}}
\end{gathered}
$$

where $R$-radius of the circular load plate, $D_{i}$-deflection of the $i$-th geophone and $i-$ distance in millimeter from the center of the load plate.

\subsection{Description of the Structure}

The bridge is an in situ cast reinforcement concrete bridge. The crossing girders have comparable dimensions and are joined with a reinforcement concrete deck. This makes the structure near to the so-called "plate-behavior". The limited length, related to the width of the deck, makes an analysis with the Plate Theory or a Finite Element (FE) analysis an effective way to estimate the structural behavior, since simplified beam models, such as the Eulero Bernulli's one, are not valid for it. The considered bridge structure is composed of a concrete deck with trellis girders measuring $11.86 \mathrm{~m}$ (length) and $15.45 \mathrm{~m}$ (width). The thickness of the deck, also considering that the road pavement, is $45 \mathrm{~cm}$. The intradoses cross-beam are casted on site. In Figure 4 is drawn the planimetric view and the structural cross-section of the deck. This is characterized by eight primary bearing beams (in Section B-B) and four diaphragms in the transverse section (Section A-A), with the support diaphragm of double thickness, as compared to the central ones. The primary beams are of T-shape with an overall height of about $90 \mathrm{~cm}$ and a thickness of $35 \mathrm{~cm}$. The transverse girders are 90 per $30 \mathrm{~cm}(60 \mathrm{~cm}$ the ones placed on the side).

The bridge was preliminarily investigated with pull out, sclerometer and coring tests, to assess the concrete compression strength. The asphalt was similarly assessed: Mechanical data of the numerical model are summarized in Table 1.

The visual inspection of concrete (Figure 5) revealed a high level of spalling, whilst the steel rebars revealed a high level of corrosion. The original shear strength was made by stirrups and longitudinal profiled ties. A relevant number of cracked stirrups (on the combined effect of load and aggressive environmental conditions) highlighted a relevant risk of brittle shear failure.

The Fast-FWD tests campaign was performed in May 2019, in one single hour. In Figure 6, an aerial view shows the bridge road and the testing site. On each of the 48 testing points, three load impulses were applied with increasing contact pressure, respectively, of 1300, 1400 and $1500 \mathrm{kPa}$.

Table 1. Mechanical properties for the Finite Element (FE) model.

\begin{tabular}{cccccc}
\hline \multicolumn{2}{c}{ Concrete } & \multicolumn{2}{c}{ Asphalt } & \multicolumn{2}{c}{ Steel } \\
\hline $\mathrm{E}_{\mathrm{c}}(\mathrm{GPa})$ & $\boldsymbol{v}_{\mathrm{c}}$ & $\mathrm{E}_{\mathbf{a}}(\mathrm{GPa})$ & $\boldsymbol{v}_{\mathrm{a}}$ & $\mathrm{E}_{\mathbf{s}}(\mathrm{GPa})$ & $\boldsymbol{v}_{\mathrm{s}}$ \\
\hline 10.52 & 0.35 & 1.50 & 0.35 & 206 & 0.20 \\
\hline
\end{tabular}




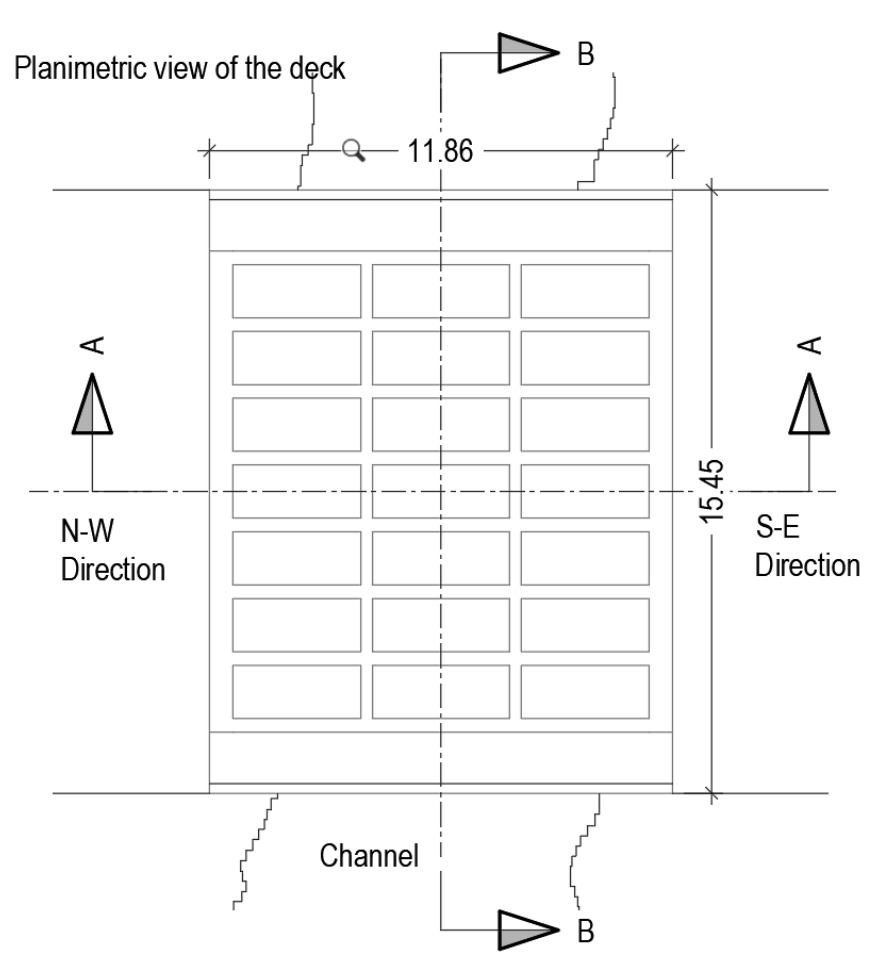

(a)
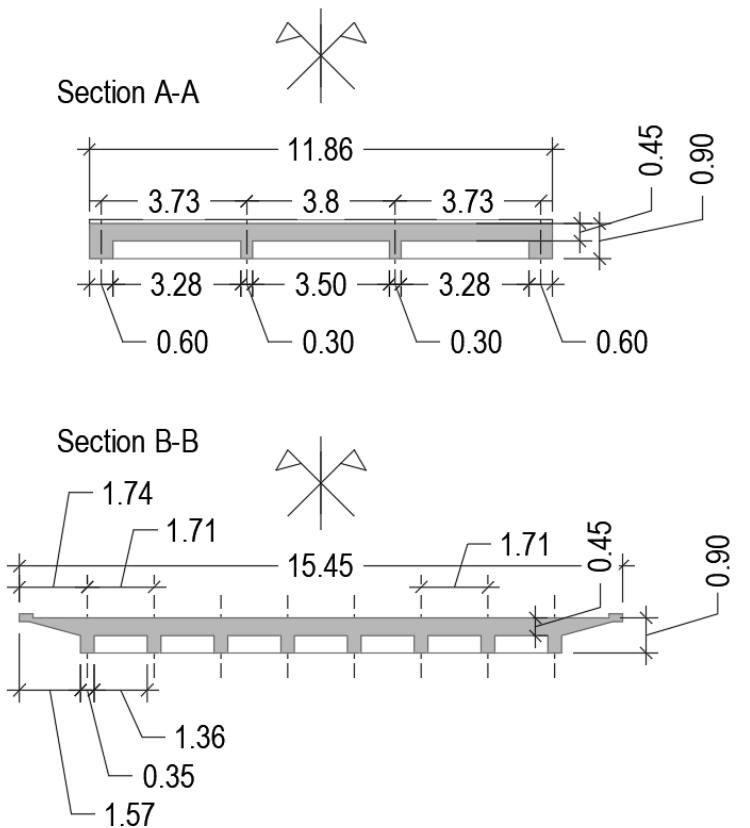

Figure 4. View of the deck: (a) planimetric view of the trellis girder and (b) longitudinal and transversal sections.

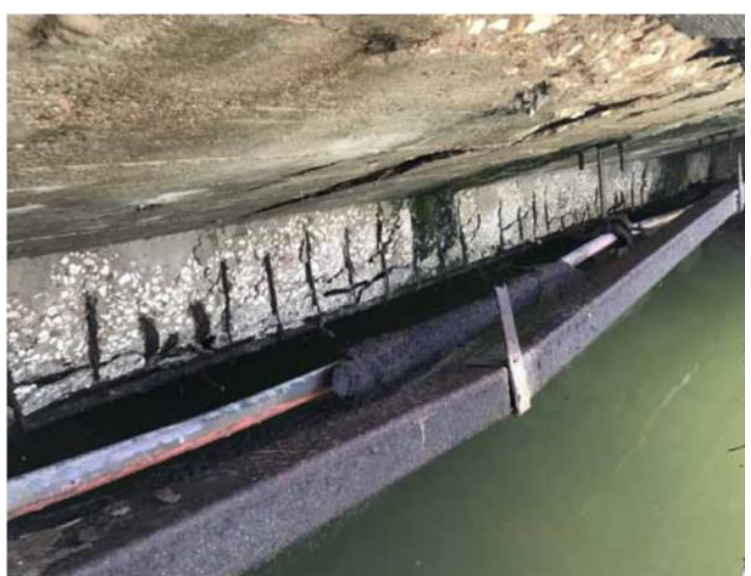

(a)

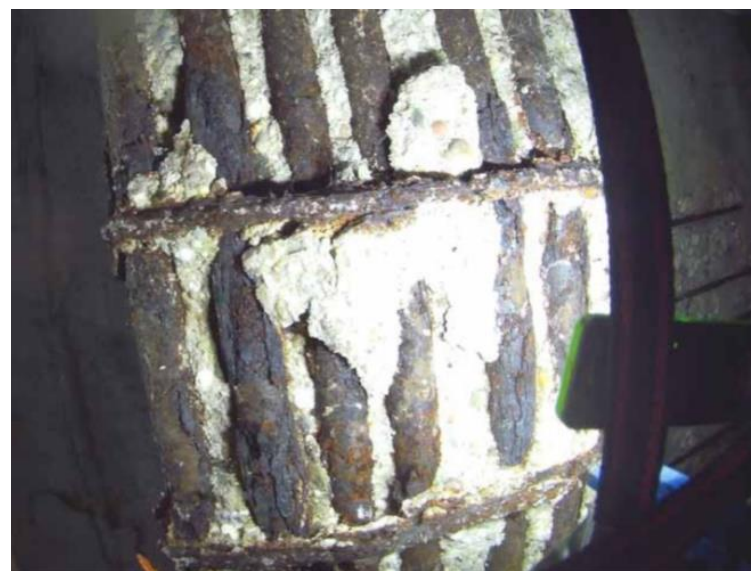

(b)

Figure 5. Picture of the bridge, showing significant corrosion: (a) lateral view of the deck and (b) view of the intrados of the beam.

Before tests, a geometric grid was established on the deck of the bridge, whose origin of the reference system is in Figure 6. Testing-point positions are in Figure 7 and the positions of the geophones are in Figure 7. Comparing Figure 7 with Figure 4, it is evident that the test net is different from the structural net of girders. This is motivated by the fact that test net is established with the criteria to measure equally spaced points on all the bearing surface of the bridge, aside from the actual position of the bearing element. This is done in order to validate the method, also in the case of lack of knowledge of the structural net that is sustaining the deck. 
The Fast-FWD Load Cell is a low-profile shear web designed with strain gauges. Despite its high range of $250 \mathrm{kN}$, it features a height of only $45 \mathrm{~mm}$. Due to design specifications, the cell will deflect less than 30 microns at peak load. Nominal sensitivity is approximately $16 \mu \mathrm{V} / \mathrm{V} / \mathrm{kN}$.

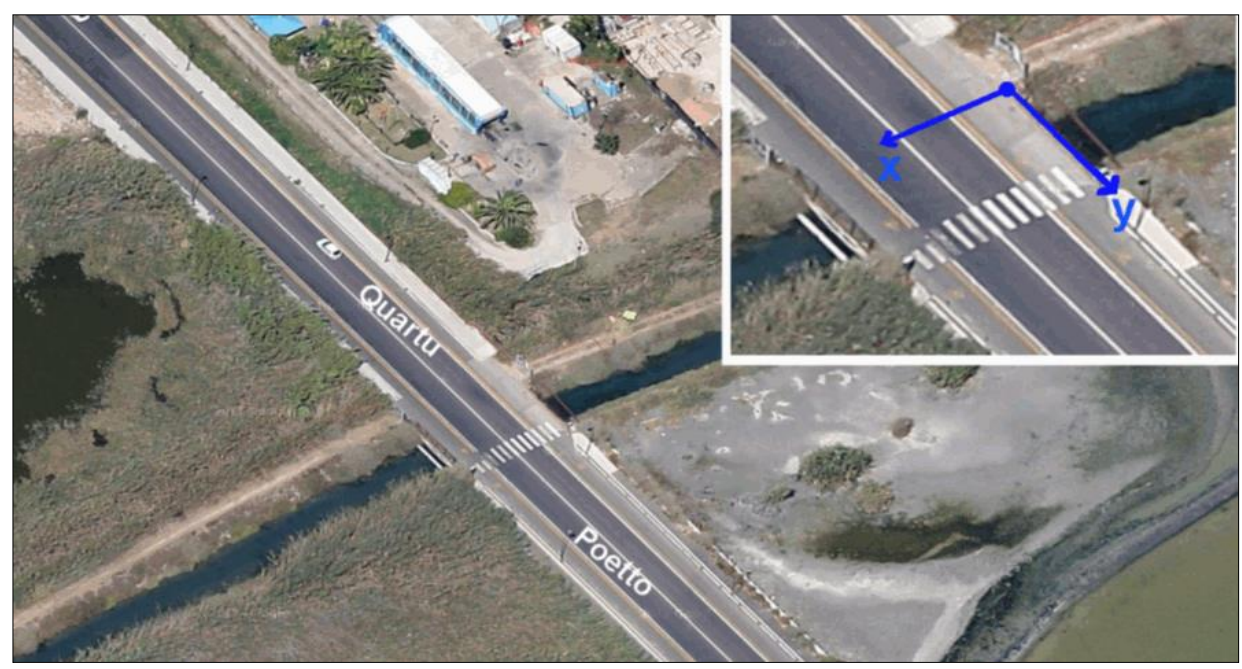

Figure 6. Aerial view of the testing site.

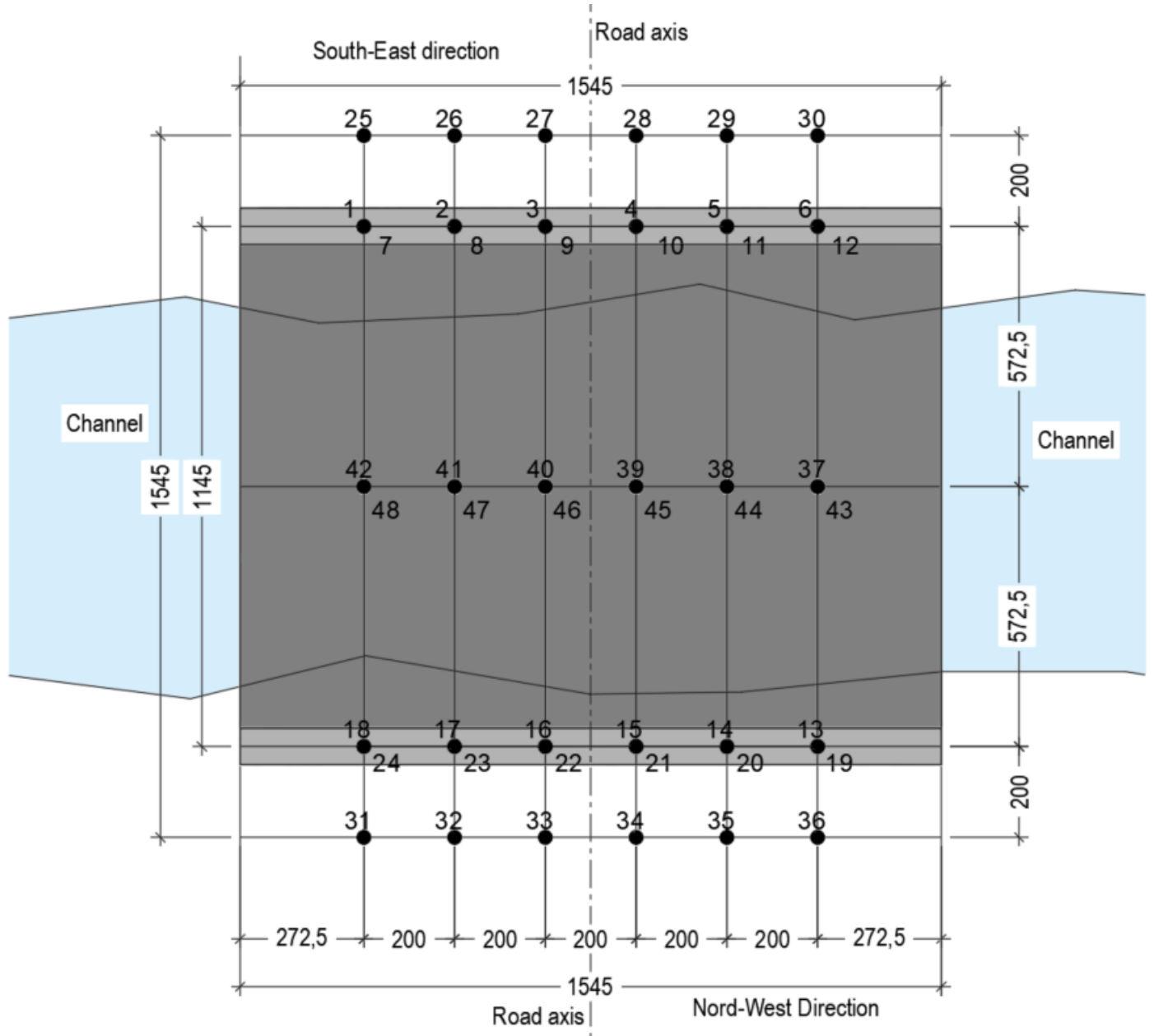

Figure 7. Survey grid and schematic position of the station points. 
The twelve geophonic sensors should be very robust and with high-precision transducing seismic velocity, protected in a sealed housing. The available movement is $\pm 2 \mathrm{~mm}$ with $2 \mu \mathrm{m}$ precision. The displacements are determined by integrating geophones' signal. Load cell and geophones are both calibrated periodically and before daily use, according AASHTO R32-11 protocol [43].

All tests performed had the bar that holds the geophones aligned along the $y$-axes. Thus, the longitudinal deflection of the girder was also reordered. Tests performed on the middle line of deck and on the abutment were performed twice in the same position, with the geophone bar once facing Quartu (N-W) and then Poetto (S-E). Each test is identified by a number from 1 to 48 . The tests on the approach pavement were performed only once (Figure 7).

The impulse duration was $30 \mathrm{~ms}$; the 1200 values of displacements and load were recorded for each drop (i.e., one value every $0.05 \mathrm{~ms}$ ), recording $60 \mathrm{~ms}$ for each test. An average load and displacement were determined for each tested point, obtaining a time history basin deflection stiffness value for the bridge for each tested position.

\subsection{Numerical Simulations}

The FE model was developed in ANSYS ${ }^{\mathrm{TM}}$ Mechanical (see Figure 8). The mesh is made of SHELL181 Elements for the concrete beams and SOLID187 Tetrahedral Elements for the concrete slab and the asphalt roadbed. The characteristic size of each finite element is $0.15 \mathrm{~m}$.

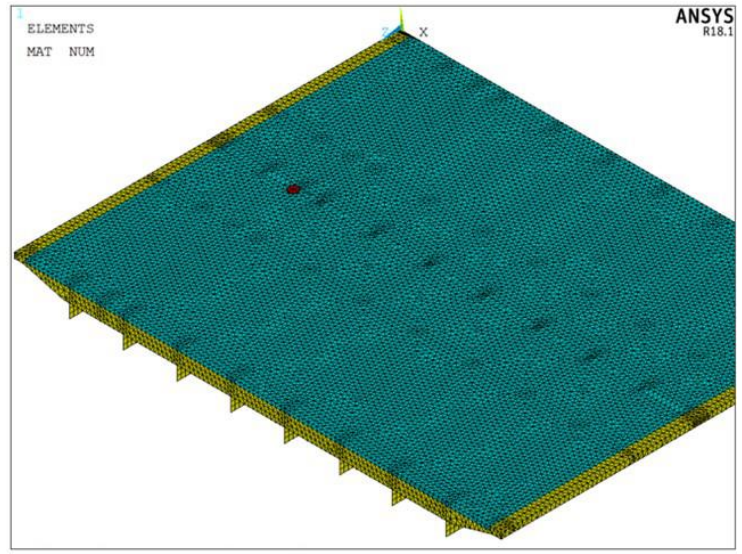

(a)

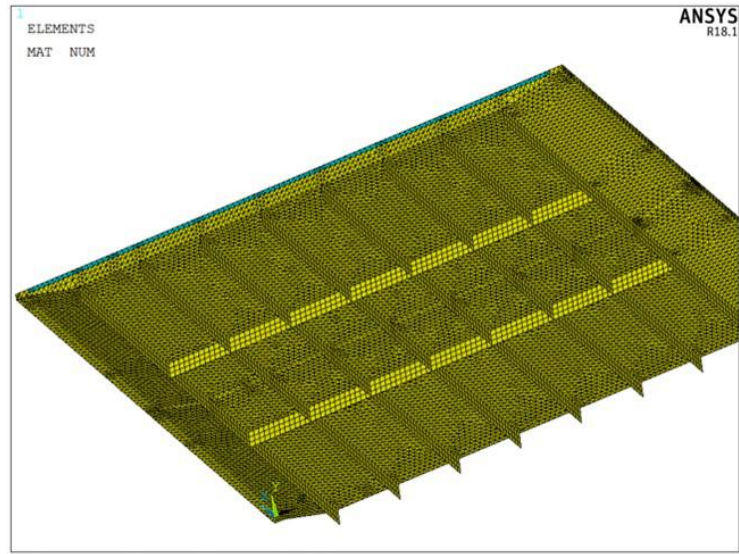

(b)

Figure 8. (a) Elements merging nodes with the ones belonging to the surface of the asphalt. (b) Thus, a rigid contact between the loading plate and asphalt is developed during the whole loading time.

Concrete, asphalt and steel properties are reported in Table 1. Moreover, the Rayleigh damping coefficients values are $\alpha=53.66$ and $\beta=0.0069$.

A first static analysis was performed, to check the reliability of the model, and the contour of vertical displacements can be seen in Figure 9. The bridge is simply supported by the abutments on the longer side; thus, the vertical displacement peak can be found, at midspan, in most external lateral edges. Then, the basin shape profile was simulated through a static analysis of the loading scenario corresponding to point 48 (Figure 7). For the sake of brevity, just three geophones (1,2 and 4 in Figure 4) were considered in the analysis.

A static load of $91.74 \mathrm{kN}$ was applied to point 48 , and the deflection in the location of each geophone was calculated and reported in Figure 10. The envelope of the maximum deflection of each geophone during the dynamic experimental test is also reported in Figure 10, confirming the accuracy of the numerical model. In addition, the maximum displacement is located near the loading plate, and the deflection is reduced as the distance from the loading plate is increased. 


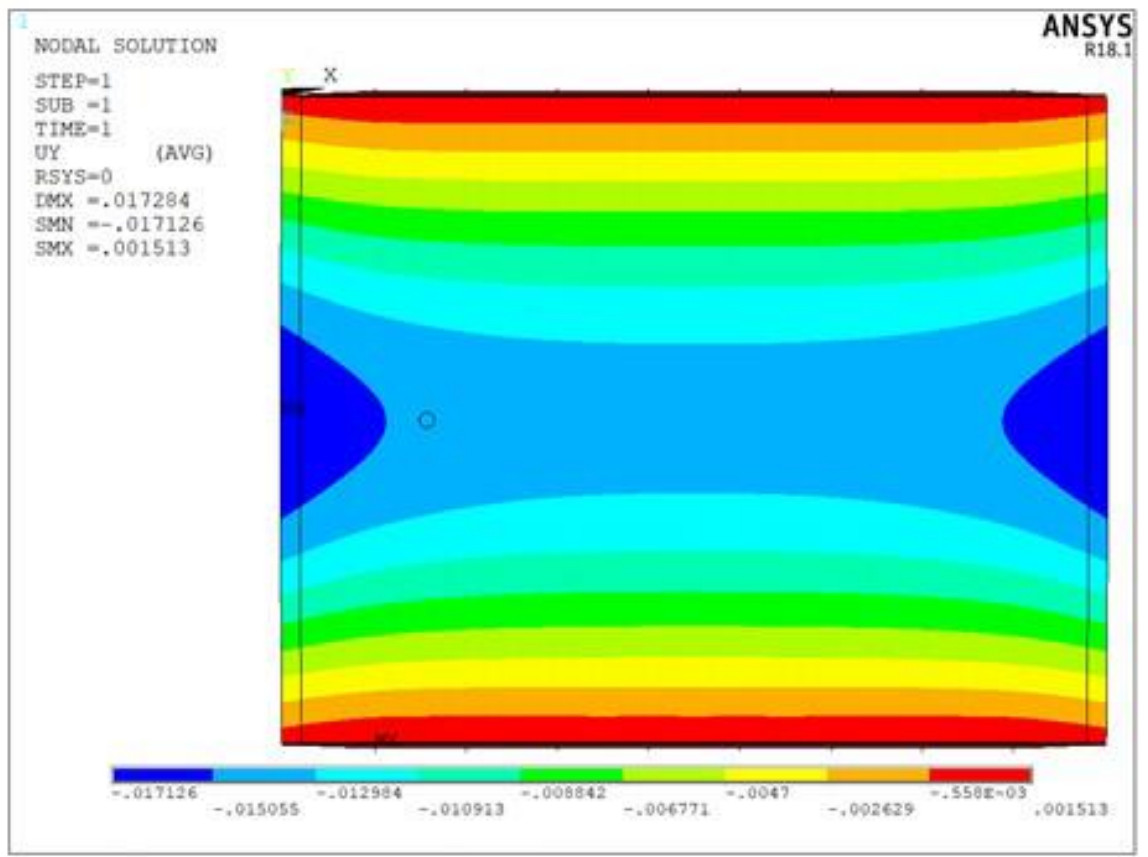

Figure 9. Contour of vertical displacement under inertia loads.

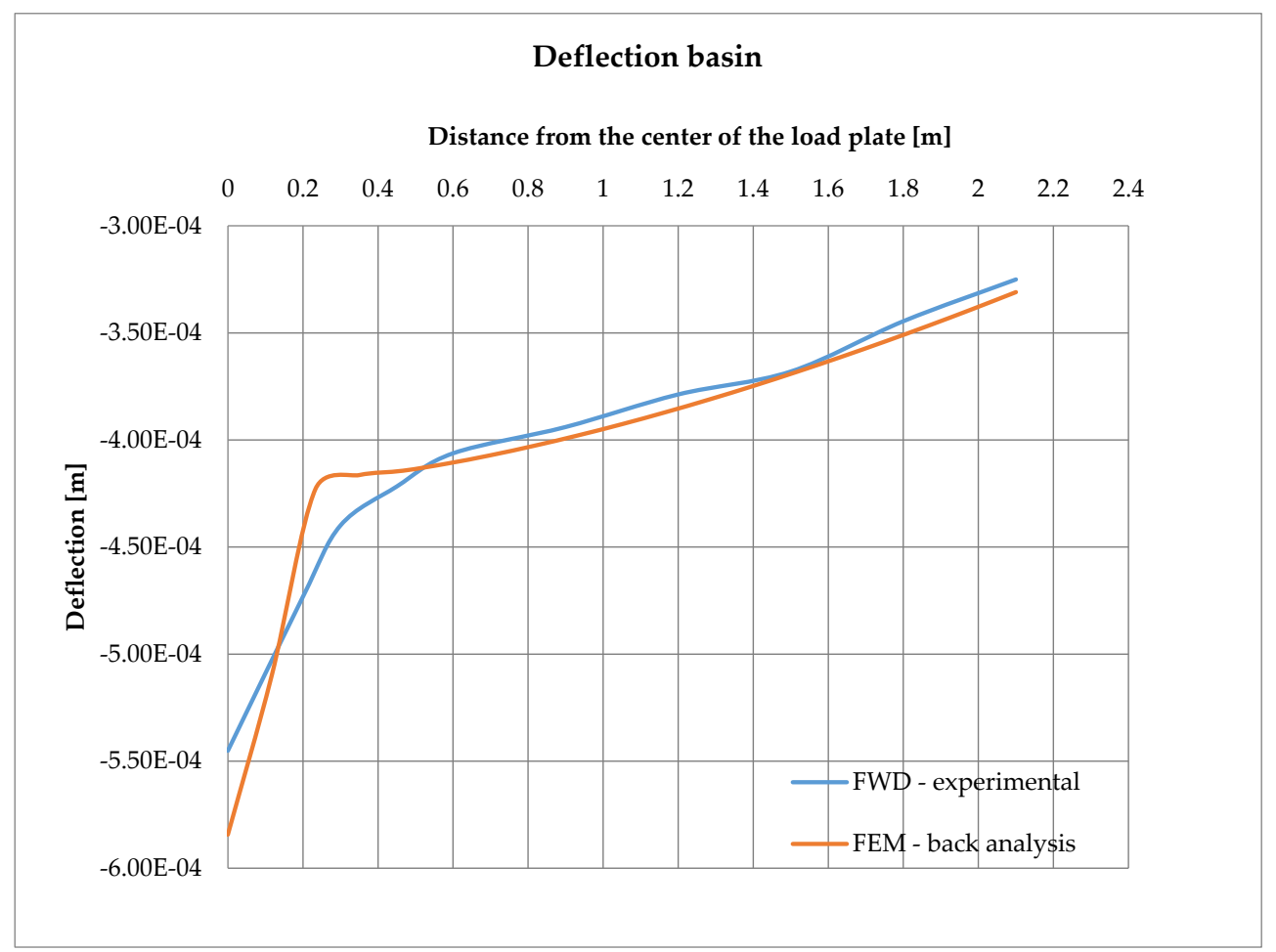

Figure 10. Comparison between experimental and numerical basin shape profile for load point 48 .

A transient analysis was able to represent the Fast-FWD dynamic load on the structure. The load is applied as a transient force on the loading plate, and the time-history of the deflection recorded in the positions of each geophone is recorded (Figure 11). The selected time step is $\Delta t=1 \mathrm{~ms}$. It represents the best compromise between accuracy and computational costs reduction; indeed, with an i9-x series processor with 48 cores and $128 \mathrm{~Gb}$ of RAM, it is possible to obtain the transient results in $25 \mathrm{~min}$. 


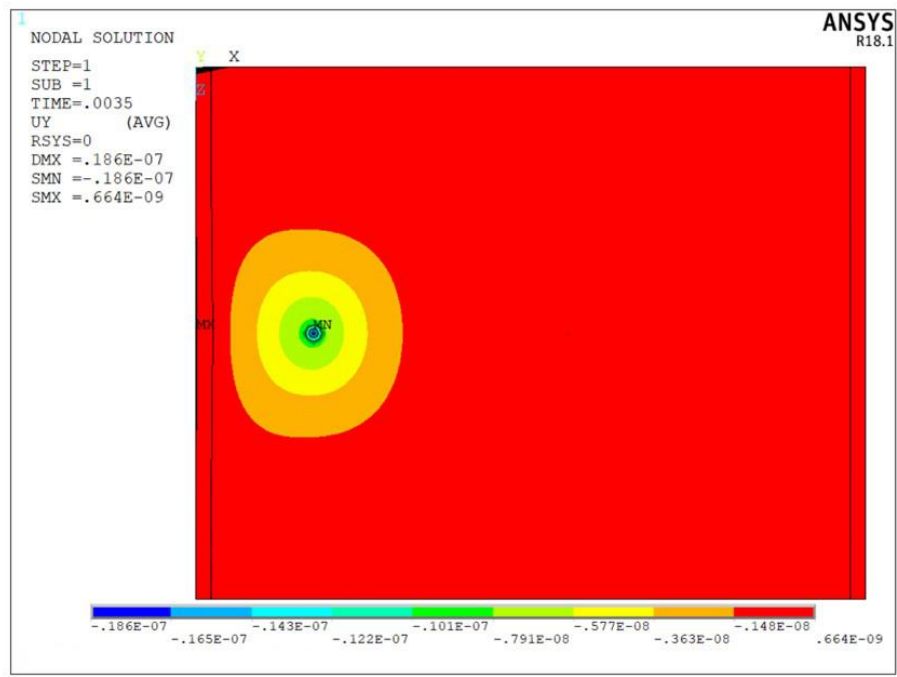

(a)

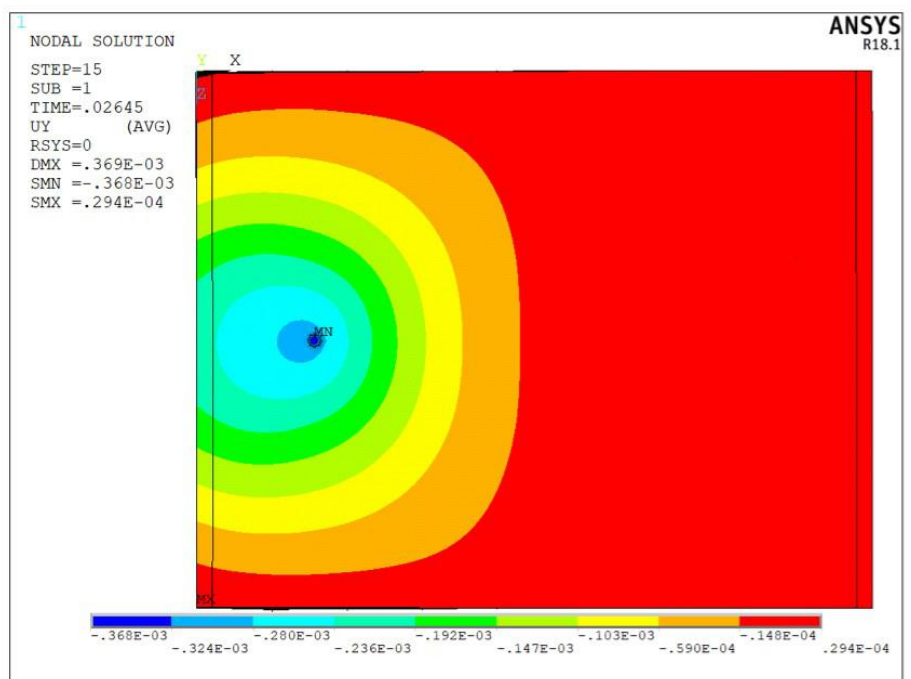

(b)

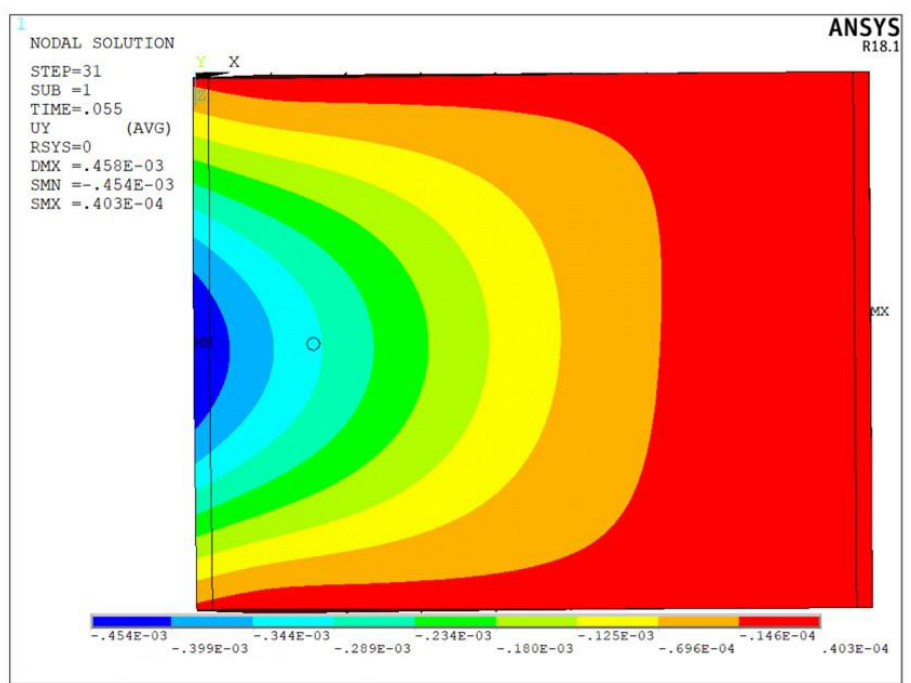

(c)

Figure 11. Vertical displacement at (a) $t=3.5 \mathrm{~ms},(\mathbf{b}) \mathrm{t}=26 \mathrm{~ms}$ and (c) $t=55 \mathrm{~ms}$ for the load at point 48 . 
For the sake of synthesis, in the following, we consider just the loading condition in which the Fast-FWD load plate is in point 48 . The contour of the vertical displacements at different time steps is shown in Figure 12. It can be seen how the load wave is moving from the loading plate to the positions of the geophones. A first comparison between the deflection measured by the geophones in the field and the corresponding simulation is shown in Figure 12. The general trend of the FE results is almost similar to the experimental ones. However, in dynamic analysis, it is possible to highlight a difference in the amplitude and a time lag in maximum point. Figure 13 shows a significant diversion in the peak than in the relative abscissa. The structural behavior of the bridge is not straightforward, considering that the damages present in the bridge strongly affect its performance. More accurate models will be developed in the future, considering also the data coming from the Fast-FWD.

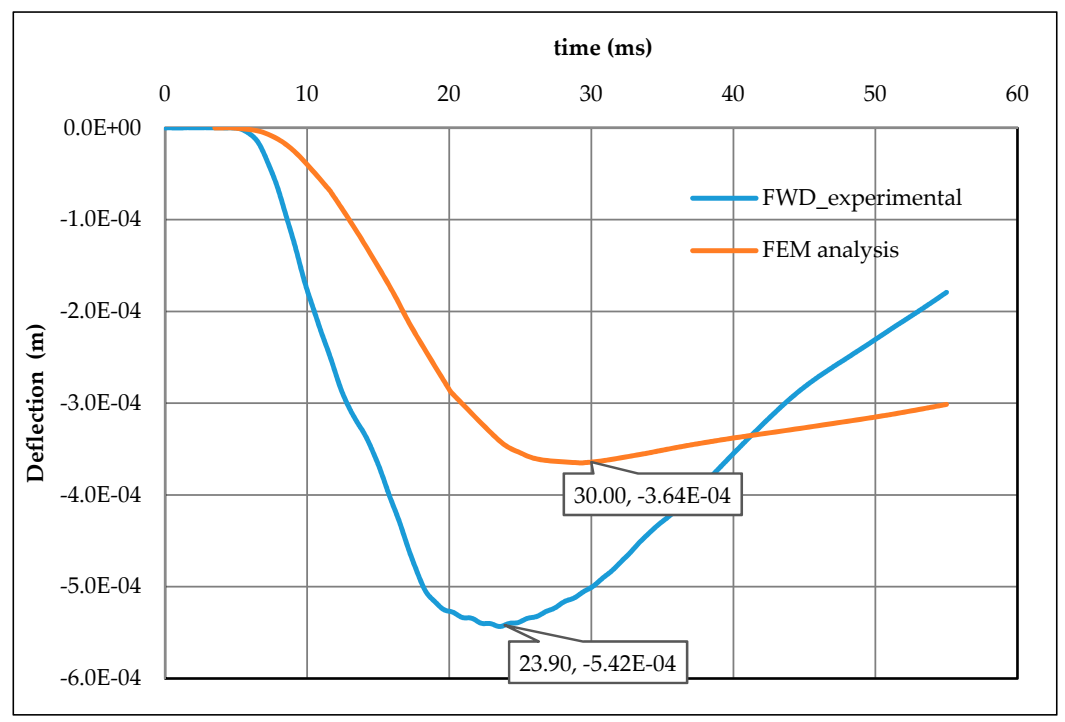

(a)

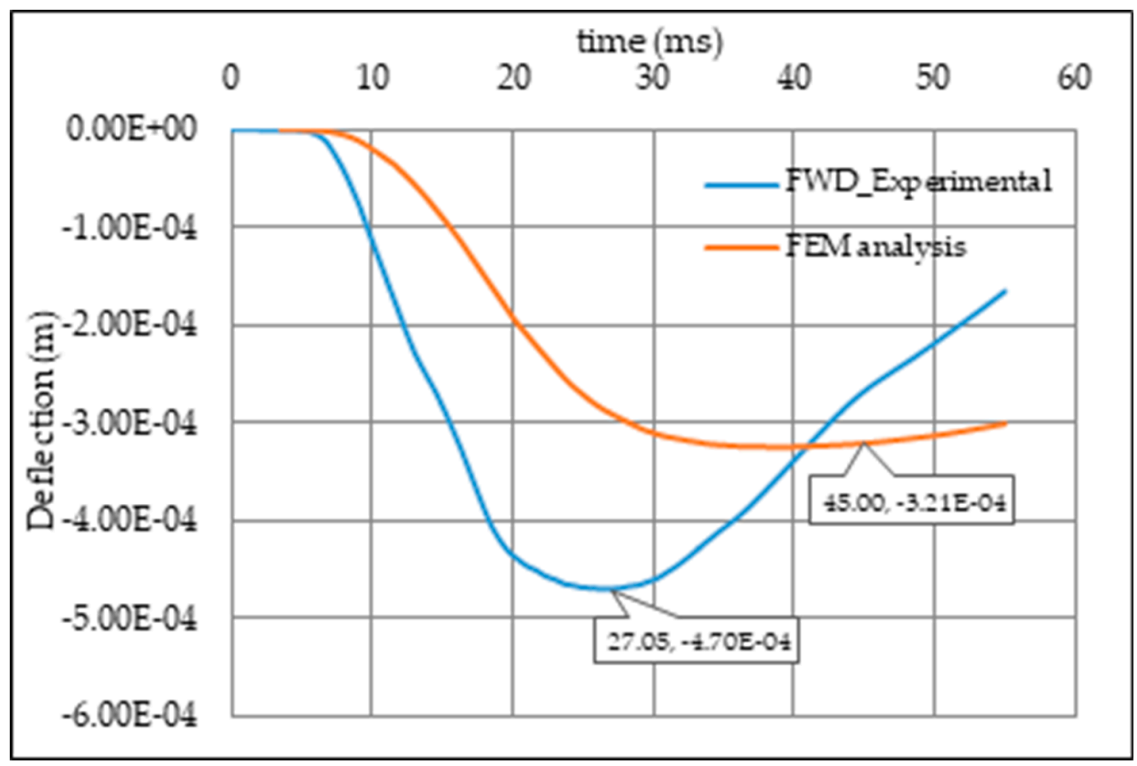

(b)

Figure 12. Cont. 


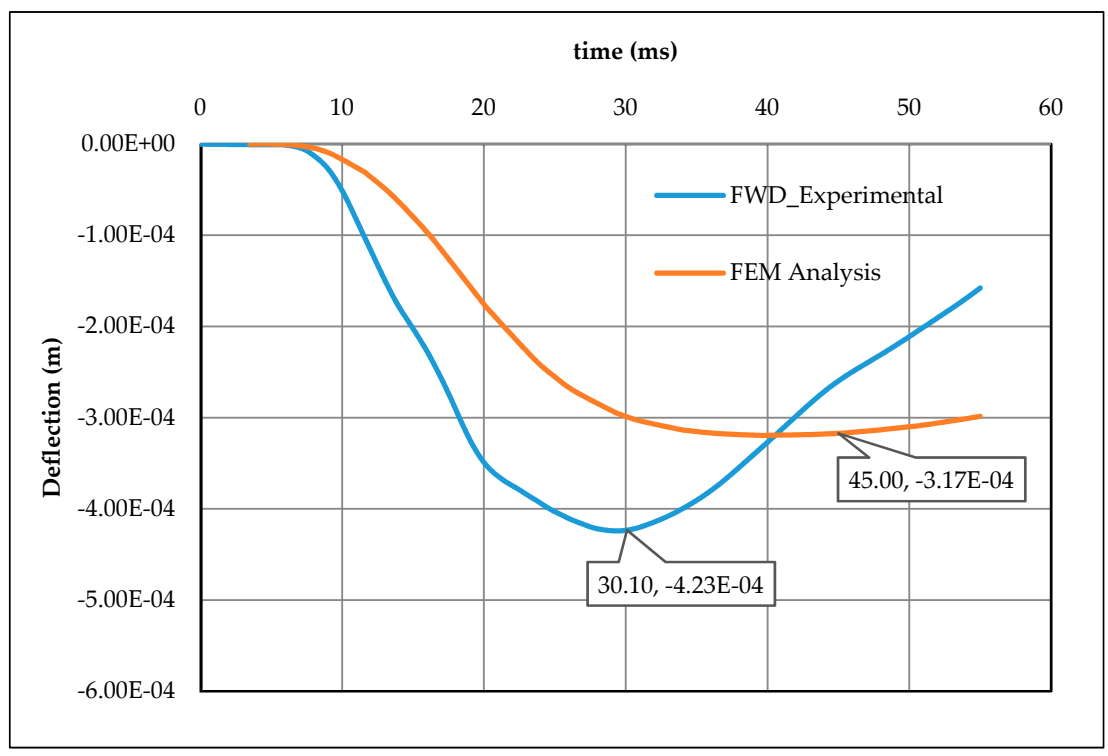

(c)

Figure 12. Comparison between experimental and numerical time history of geophone displacements. Geophone 1 (a), Geophone 2 (b) and Geophone 4 (c).

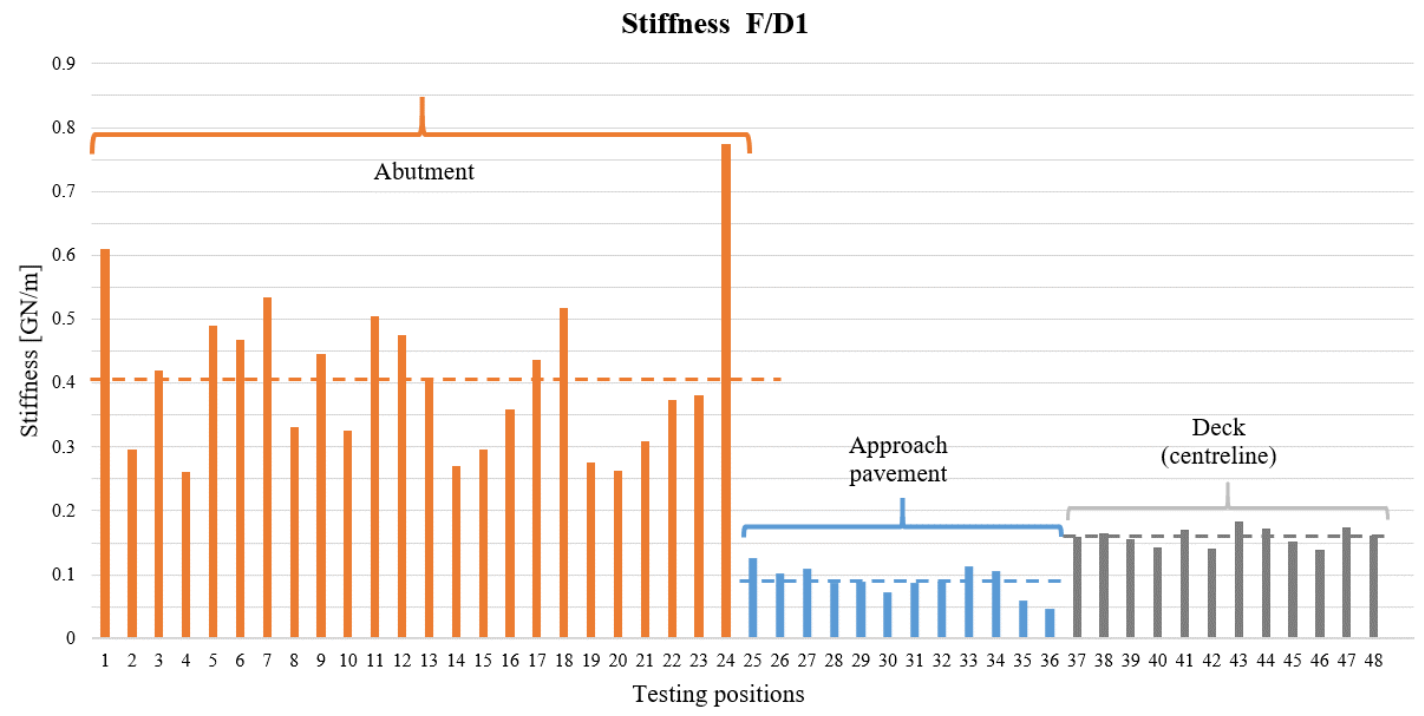

Figure 13. Average values of stiffness for the tested points.

\section{Results and Discussion}

In the center of the deck (test points 37-48, Figure 8), deflection test values are between 599 and $638 \mu \mathrm{m}$, while tests performed on the abutment (test points 1-24, see Figure 8) show deflection values between 272 and $285 \mu \mathrm{m}$ (N-W side) and 238 e $248 \mu \mathrm{m}$ along (S-E side). Considering, instead, the approach pavement (test points 25-36), higher values of deflection were measured, that is, 981 e $1094 \mu \mathrm{m}$ (S-E side) and 1212 e $1368 \mu \mathrm{m}$ (N-W side).

The average value of stiffness in the center of the deck was of $0.16 \mathrm{GN} / \mathrm{m}$, while, on the two abutments, an average value of di $0.41 \mathrm{GN} / \mathrm{m}$ was measured (Figure 13). The approach pavement had an average stiffness value of $0.091 \mathrm{GN} / \mathrm{m}$.

The above stiffness is significant to evaluate the condition and deterioration of bridges over time, throughout repeated tests $[5,44]$. Moreover, the stiffness values of the abutment are greater than those measured on the center of the deck and on the approach pavement. In Figure 14 are plotted the values of the stiffness on the deck of the bridge. 


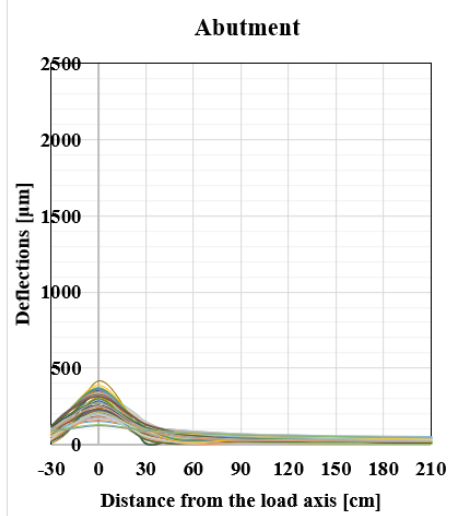

(a)

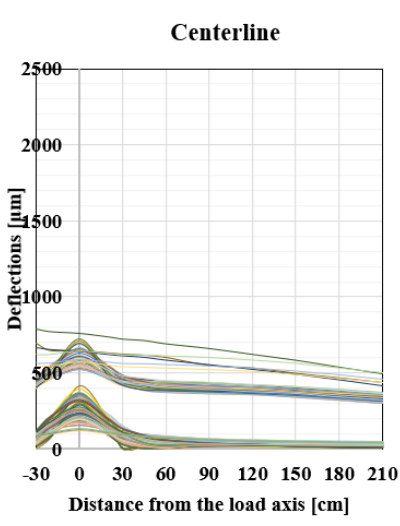

(b)

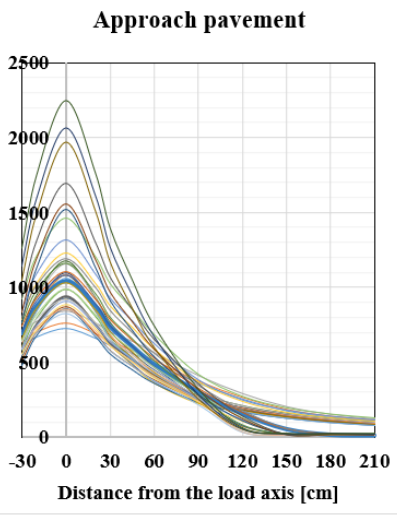

(c)

Figure 14. Deflection basin on the: abutment (a), centerline of the bridge (b) and approach pavement (c).

The indexes introduced in Section 2.1 indicate the condition of the layers placed at different depths. Those are plotted in Figures 15-18. The Federal Highway Administration (FHA) gives tables [41] with the limits of acceptability of the indexes for road pavement, depending on the kind of material. Reinterpretation of the deflection basin parameters can be used to investigate other non-standard situations, such stone pavement, airport pavement instrumentation and pavement management system [45-47].

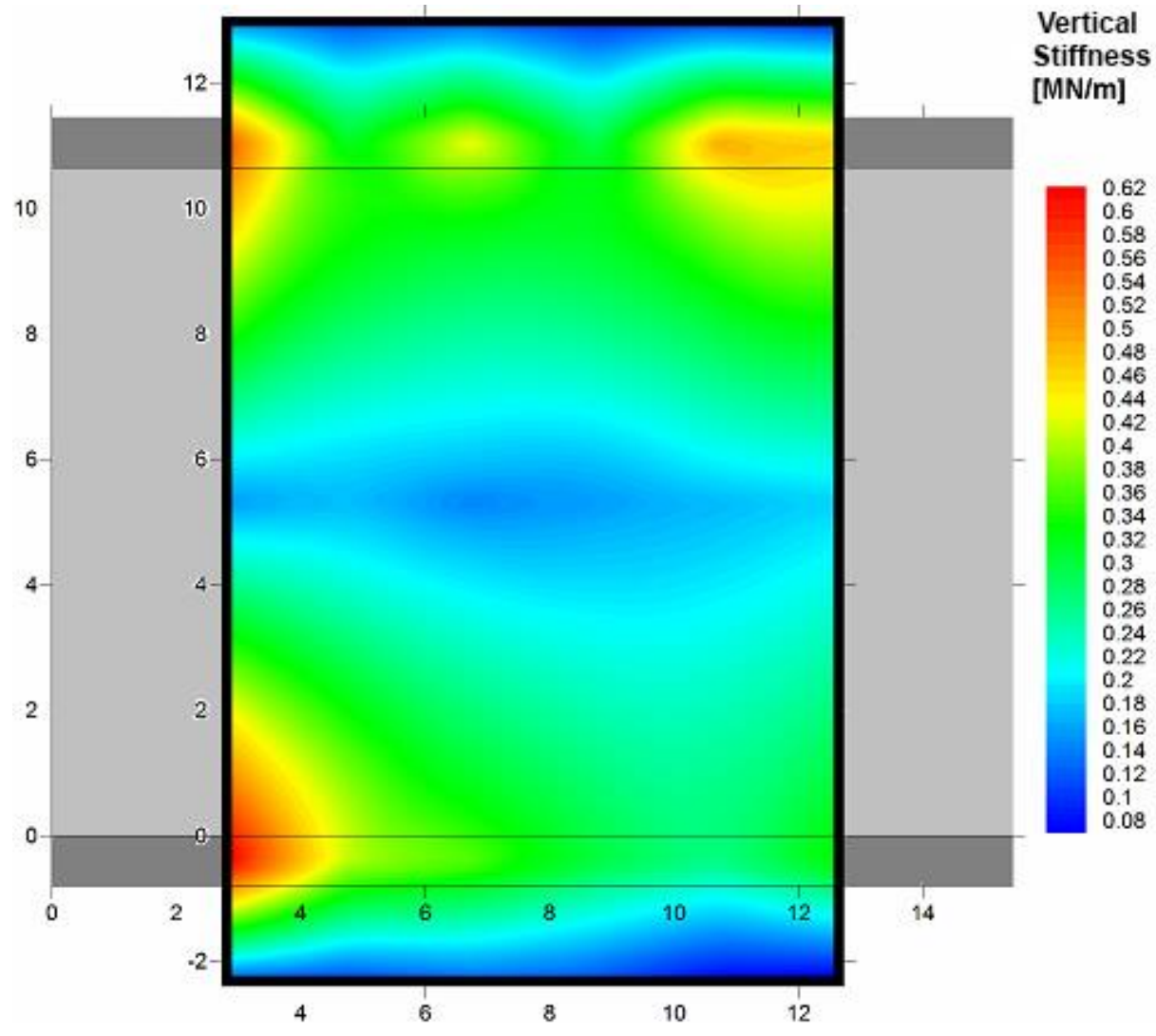

Figure 15. Contour of stiffness values.

It can be highlighted that the Fast-FWD allows us to induce a significant vertical impulse to the deck, like the one induced by a big sclerometer. This impulse can be 
analyzed throughout different indexes. The more significant is probably the stiffness K. The maximum displacements of the Fast-FWD test are from the 33\% (Figure 12c) to the $49 \%$ (Figure 12a) greater than the one attended from the FE model. This is a clear indicator of the degradation of the deck.

The contours of Figures 16-18 show the variation of the vertical stiffness and of the Basin Indexes. The color maps are derived by the point measures made, as shown in Figure 8. The interpolation of the tests was carried out with the software Surfer rel. 8.

Figure 16 illustrates that vertical stiffness varies in the range $0.00-0.65 \mathrm{MN} / \mathrm{m}$. Figures 17 and 18 illustrated, respectively, SCI, BDI and DCI in $\mu \mathrm{m}$, indicators that reveal the condition of the investigated pavements and structural layers.

The variation of these indexes on the surface of the bridge is an interesting indicator of the response of the surrounding structural layer. This is more significant for bridges in which the depth of the pavement is very thin. All the indexes represented in the graphs bellow present some range of variation in a different zone of the deck that represents a different structural response induced by aging.

By providing the reduced depth of the road pavement on the bridge deck, the Base Distress Index (BDI) can be considered an interesting indicator for the structural response. For example, the BDI in the centerline varies between 20 and 80 . Thus, the BDI, here, is a relevant indicator of the differential corrosion of the reinforcement of the bridge. An accurate record of the response of the bridge is recommended at different abscissa in various positions (both on the crossbeams and on the slab).

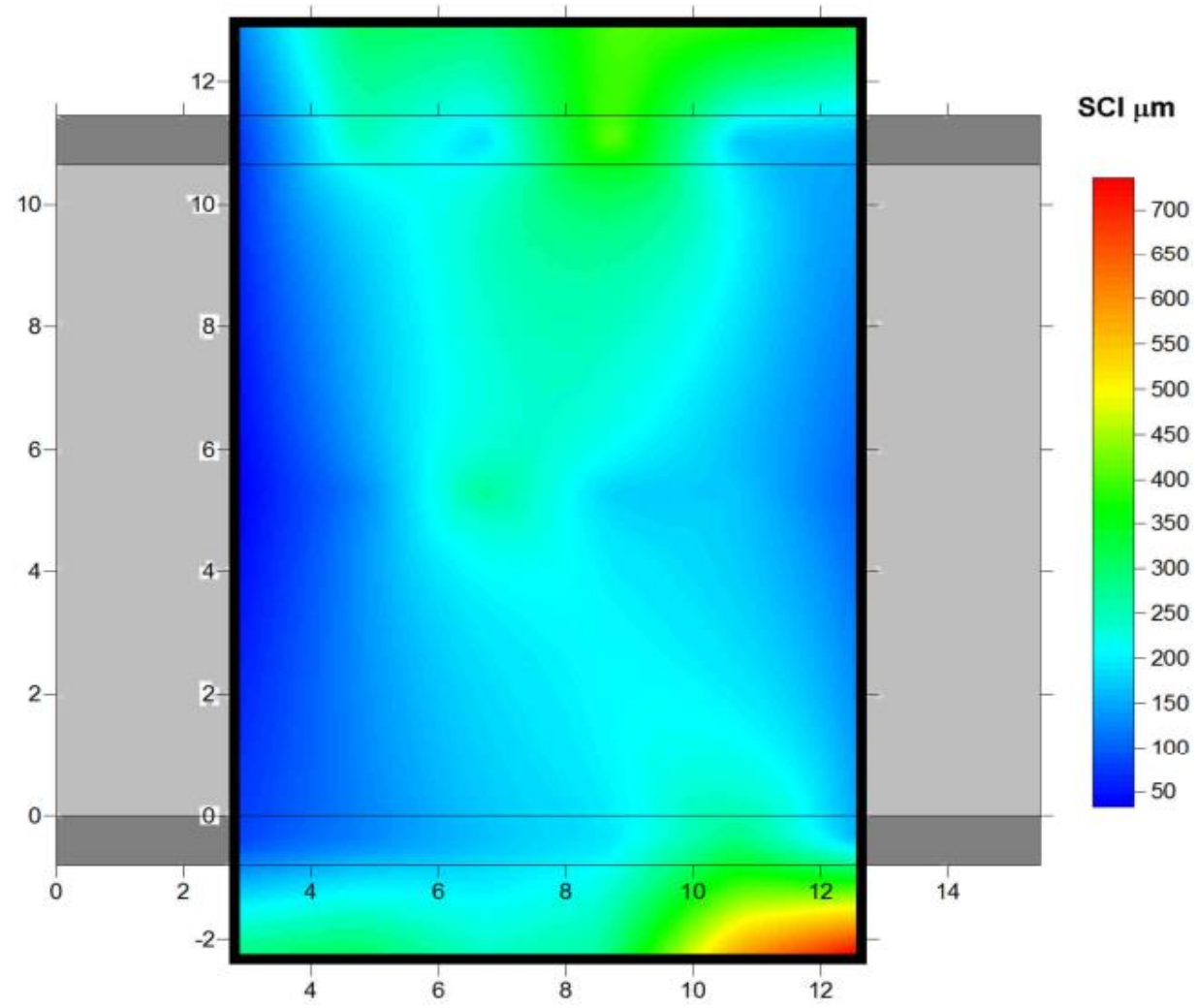

Figure 16. Contour of the Surface Condition Index (SCI). 


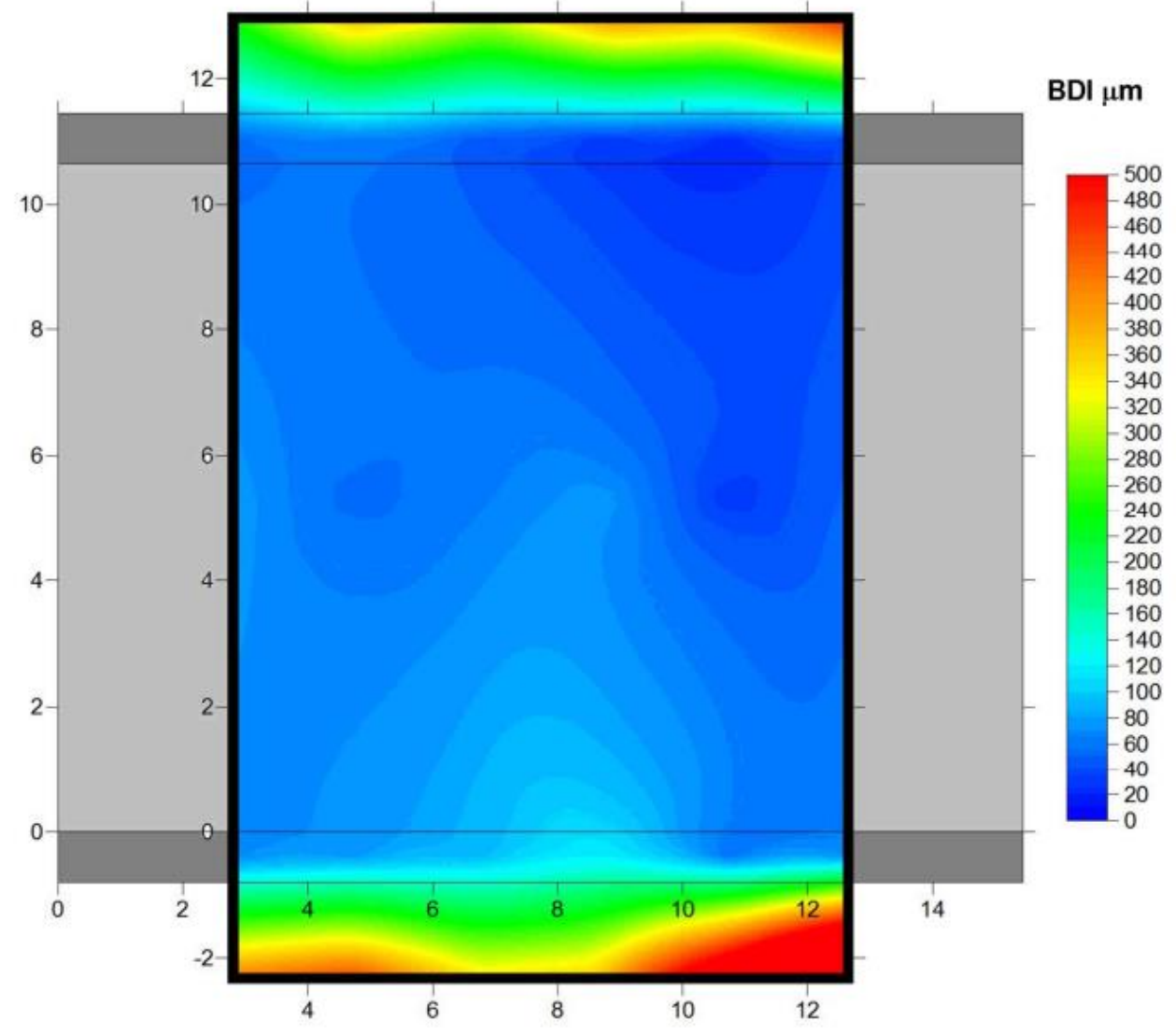

Figure 17. Contour of Base Distress Index (BDI).

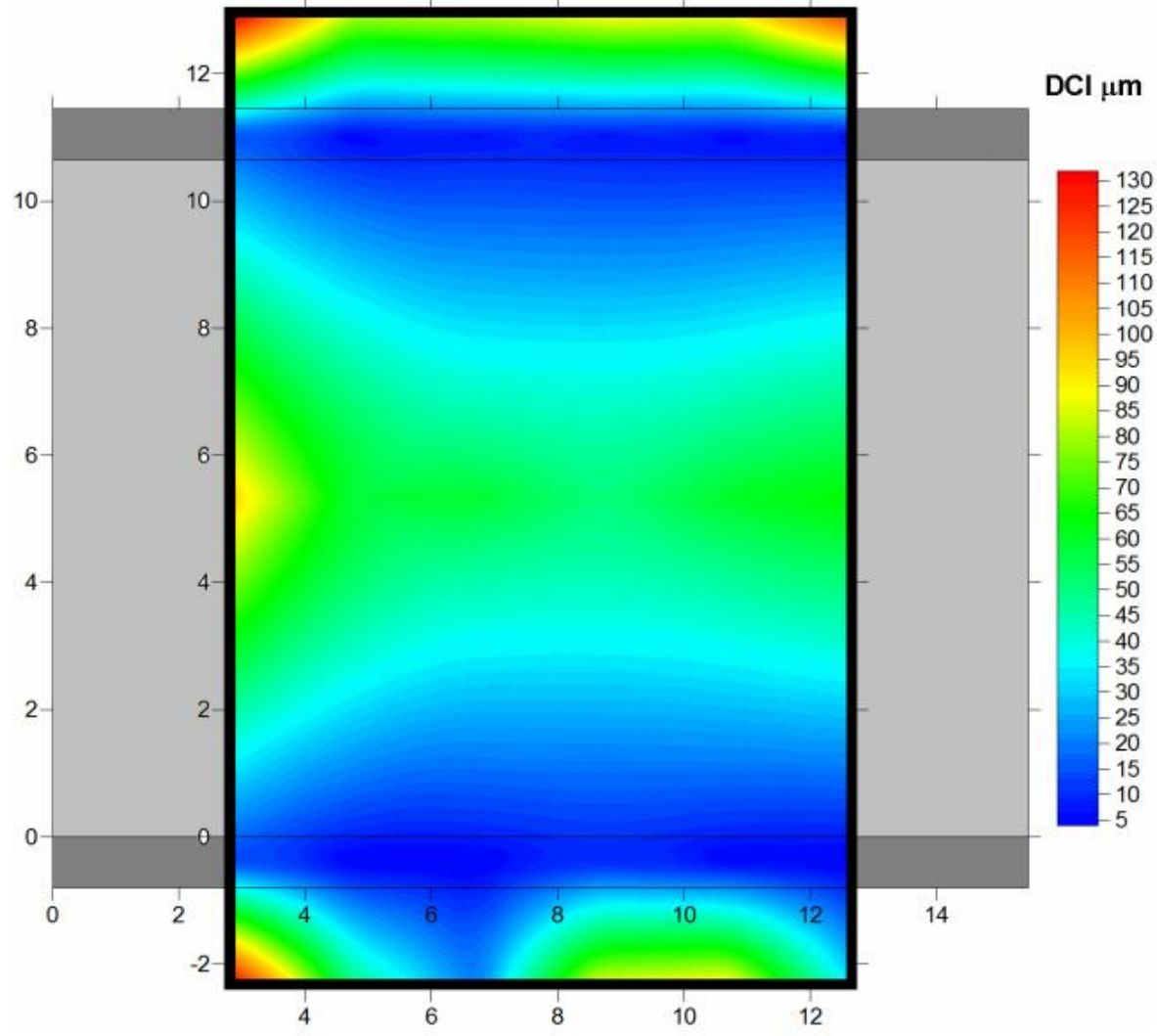

Figure 18. Contour of Deep Condition Index (DCI). 


\section{Conclusions}

The screening of existing bridge with Fast-FWD represents a promising technique for quick assessment of the vulnerability of these infrastructures. The main advantage is given by the low impact and short time necessary to record static and dynamic information from the structural behavior and the fast back calculation procedure. This suggests application of the Fast-FWD test for the periodical monitoring of bridges and viaducts. The variation of the mentioned indexes over time is a significant tool for assessing the effects of aging or other events on the structures.

Indeed, the deflection time histories can be a benchmark dataset for model tuning methods. In this way, it is possible to develop a theoretical model of the structure and tune input parameters (mechanical characteristics of materials, and geometrical values), to achieve numerical results similar to the tested ones.

The thread, at this point of the research, is to carry out a continuous and periodical in situ measurement on the infrastructure, to have live monitoring. An initial check (ideally made at the construction of the bridge or, if not possible, in parallel with an accurate structural screening) is needed as landmark and furnish the initial status $C_{0}$. The periodical investigation $C_{i}$ will give a continuous time monitoring of the structural state. When the measurement $C_{i}$ had a significant deviation from the initial one, $C_{0}$, a more accurate investigation is required, as in the case of study here presented.

The ongoing activity of the research teams aims to have some quantitative indication form Fast-FWD investigation through a back analysis of the infrastructure with an FE Models. This requires us to study several case of study with different span and technology. The aim will be to have some abacus with a direct and quantitative relationship between Basin indexes and structural condition.

For the most recurrent beam-type structures, the response assessment can be carried out by studying different types of infrastructure and with different aging (from new bridges to structures nearing the end of their life cycle). Moreover, the evaluation of Indexes for homogeneous structures and aging condition will consent to produce specific forms and schedules with limit ranges, to simply verify the status of the bridge.

Author Contributions: Concept and methodology, M.C., F.M., M.S., and F.S.; experimental campaign and validation, M.C., F.M., M.L.P., and J.R.; analysis, F.S. and M.L.P.; writing-review and editing, M.C., F.M., M.L.P., J.R., M.S., and F.S.; project administration, M.C. and F.M. All authors have read and agreed to the published version of the manuscript.

Funding: Agreement between Metropolitan City of Cagliari and University of Cagliari $\mathrm{N}^{\circ}$ Reg. 4724.

Institutional Review Board Statement: Not applicable.

Informed Consent Statement: Informed consent was obtained from all subjects involved in the study.

Data Availability Statement: Not applicable.

Acknowledgments: The Authors thanks the Metropolitan City of Cagliari and the Quartu S.E. Municipality administrations for data collected and accessibility to the case study. The financial support is given by Autonomous Region of Sardinia, under grant PO-FSE 2014-2020, CCI: 2014IT05SFOP021, through the project "Retrofitting, rehabilitation and requalification of the historical cultural architectural heritage (R3-PAS)" is acknowledged by Flavio Stochino. The financial support is also given by the project "Monitoring of the structural and energy behaviour of existing constructions" that is acknowledged by Mario Lucio Puppio.

Conflicts of Interest: The authors declare no conflict of interest.

\section{References}

1. Sassu, M.; Giresini, L.; Puppio, M.L. Failure scenarios of small bridges in case of extreme rainstorms. Sustain. Resilient Infrastruct. 2017, 2, 108-116.

2. Ikpong, A.; Bagchi, A.; Asce, M. New Method for Climate Change Resilience Rating of Highway Bridges. J. Cold Reg. Eng. 2015, 29, 04014013. [CrossRef] 
3. Biezma, M.V.; Schanack, F. Collapse of steel bridges. J. Perform. Constr. Facil. 2007, 21, 398-405. [CrossRef]

4. Patjawit, A.; Kanok-Nukulchai, W. Health monitoring of highway bridges based on a Global Flexibility Index. Eng. Struct. 2005, 27, 1385-1391. [CrossRef]

5. Frangopol, D.M.; Biondini, F. Bridge design, maintenance and management. Struct. Infrastruct. Eng. 2014, 10, 419. [CrossRef]

6. Puppio, M.L.; Novelli, S.; Sassu, M. Failure evidences of reduced span bridges in case of extreme rainfalls the case of Livorno. Frat. ed Integrita Strutt. 2018, 12, 190-202. [CrossRef]

7. Puppio, M.L.; Novelli, S. The case of Livorno. Des. Civ. Environ. Eng. 2018, 46, 190-202.

8. Catbas, F.N.; Aktan, A.E. Condition and damage assessment: Issues and some promising indices. J. Struct. Eng. 2002, 128, 1026-1036. [CrossRef]

9. Titi, A.; Biondini, F.; Frangopol, D.M. Cost-based recovery processes and seismic resilience of aging bridges. In Maintenance, Monitoring, Safety, Risk and Resilience of Bridges and Bridge Networks, Proceedings of the 8th International Conference on Bridge Maintenance, Safety and Management, IABMAS 2016, Paraná, Brazil, 26-30 June 2016; Taylor \& Francis Group: London, UK, 2016; pp. 198-205.

10. Stochino, F.; Bedon, C.; Sagaseta, J.; Honfi, D. Robustness and resilience of structures under extreme loads. Adv. Civ. Eng. 2019, 2019, 4291703. [CrossRef]

11. Ahmed, H.; La, H.M.; Gucunski, N. Review of non-destructive civil infrastructure evaluation for bridges: State-of-the-art robotic platforms, sensors and algorithms. Sensors 2020, 20, 3954.

12. Gardoni, P.; Mosalam, K.M.; der Kiureghian, A. Probabilistic seismic demand models and fragility estimates for RC bridges. J. Earthq. Eng. 2003, 7, 79-106. [CrossRef]

13. Pucci, A.; Puppio, M.L.; Giresini, L.; Sousa, H.; Matos, J.C.; Sassu, M. Method for sustainable large-scale bridges survey. In Towards a Resilient Built Environment Risk and Asset Management; International Association for Bridge and Structural Engineering: Zürich, Switzerland, 2019; pp. 1034-1041.

14. Pucci, A.; Puppio, M.L.; Giresini, L.; Matos, J.; Sousa, H. Sustainable safety evaluation of roads network in case of extreme weather events. In Proceedings of the INCER-International Conference of Engineering Risk, Beirut, Lebanon, 3-5 April 2019 ; p. 01016.

15. Concu, G.; Trulli, N. Concrete defects sizing by means of ultrasonic velocity maps. Buildings 2018, 8, 176. [CrossRef]

16. Concu, G.; Nicolo, B.; Pani, L.; Trulli, N.; Valdés, M. Prediction of Concrete Compressive Strength by Means of Combined Non-Destructive Testing. Adv. Mater. Res. 2014, 894, 77-81. [CrossRef]

17. Pani, L.; Francesconi, L. Ultrasonic Test on Recycled Concrete: Relationship among Ultrasonic Waves Velocity, Compressive Strength and Elastic Modulus. Adv. Mater. Res. 2014, 894, 45-49. [CrossRef]

18. Xu, J.; Dolan, J.D. Development of a Wood-Frame Shear Wall Model in ABAQUS. J. Struct. Eng. 2009, 135, 977-984. [CrossRef]

19. Jiang, L.; Zhang, Y.; Feng, Y.; Zhou, W.; Tan, Z. Dynamic response analysis of a simply supported double-beam system under successive moving loads. Appl. Sci. 2019, 9, 2162. [CrossRef]

20. Concu, G.; Nicolo, B.; Pani, L. Non-destructive testing as a tool in reinforced concrete buildings refurbishments. Struct. Surv. 2011, 29, 147-161. [CrossRef]

21. Peña, F.; Prieto, F.; Lourenço, P.B.; Costa, A.C.; Lemos, J.V. On the dynamics of rocking motion of single rigid-block structures. Earthq. Eng. Struct. Dyn. 2007, 36, 2383-2399. [CrossRef]

22. Catbas, F.N.; Brown, D.L.; Aktan, A.E. Use of Modal Flexibility for Damage Detection and Condition Assessment: Case Studies and Demonstrations on Large Structures. J. Struct. Eng. 2006, 132, 1699-1712. [CrossRef]

23. Pańtak, M. Ground reaction forces generated by runners-harmonic analyses and modelling. Appl. Sci. 2020, 10, 1575. [CrossRef]

24. Novak, M.S.; Lazarevic, D.; Atalic, J.; Uros, M. Influence of multiple-support excitation on seismic response of reinforced concrete arch bridges. Appl. Sci. 2020, 10, 17. [CrossRef]

25. Zhang, Z.; Aktan, A.E. Application of modal flexibility and its derivatives in structural identification. Res. Nondestruct. Eval. 1998, 10, 43-61. [CrossRef]

26. Li, Z.; Swanson, J.A.; Helmicki, A.J.; Hunt, V.J. Modal contribution coefficients in bridge condition evaluation. J. Bridg. Eng. 2005, 10, 169-178. [CrossRef]

27. Catbas, F.N.; Brown, D.L.; Aktan, A.E. Parameter Estimation for Multiple-Input Multiple-Output Modal Analysis of Large Structures. J. Eng. Mech. 2004, 130, 921-930. [CrossRef]

28. Liu, C.; DeWolf, J.T. Effect of Temperature on Modal Variability of a Curved Concrete Bridge under Ambient Loads. J. Struct. Eng. 2007, 133, 1742-1751. [CrossRef]

29. Stochino, F.; Fadda, M.L.; Mistretta, F. Low cost condition assessment method for existing RC bridges. Eng. Fail. Anal. 2018, 86, 56-71. [CrossRef]

30. Mistretta, F.; Sanna, G.; Stochino, F.; Vacca, G. Structure from motion point clouds for structural monitoring. Remote Sens. 2019, 11, 1940. [CrossRef]

31. Bamrungwong, C. Development of a Falling Weight Deflectometer (FWD) for Evaluating the Pavement Conditions; Asian Transportation Research Society: Bangkok Thailand, 2009.

32. Elbagalati, O.; Elseifi, M.; Gaspard, K.; Zhang, Z. Development of the pavement structural health index based on falling weight deflectometer testing. Int. J. Pavement Eng. 2018, 19, 1-8. [CrossRef]

33. Hoadley, P.W.; Gomez, J.P. Structural Stiffness Identification of Bridge Superstructures: Final Report; Virginia Transportation Research Council: Charlottesville, VA, USA, 1996. 
34. Catbas, F.N.; Ciloglu, K.; Celebioglu, A.; Popovics, J.S.; Aktan, A.E. Fleet health monitoring of large populations: Aged concrete Tbeam bridges in Pennsylvania. In Proceedings of the 6th Annual Int'1 Symposium on NDE for Health Monitoring and Diagnostics, Newport Beach, CA, USA, 4-8 March 2001; p. 11.

35. Turnage, R.S.; Baber, T. Field Testing of the Wolf Creek Curved Girder Bridge: Part I: Vibration Tests; Virginia Transportation Research Council: Charlottesville, VA, USA, 2009.

36. Rawn, J. Rapid Condition Assessment of Bridges by Falling Weight Deflectometer. Master's Thesis, University of Arkansas, Fayetteville, AR, USA, 2014.

37. Dynatest International. Dynatest-Fast Falling Weight Deflectometer. Available online: https://web.dynatest.com/fast-fallingweight-deflectometer-ffwd/ (accessed on 30 December 2020).

38. Grimmelsman, K.A.; Eric, V.; Carreiro, J.L.; Rawn, J.D. Rapid Bridge Condition Screening by Falling Weight Deflectometer Submitted by MBTC 3015 October 2014; Mack-Blackwell Rural Transportation Center University of Arkansas: Fayetteville, AR, USA, 2014.

39. Dynatest International. Elmod 6. Quick Start Manual; Dynatest International A/S: Ventura, CA, USA, 2016 ; pp. 1-71.

40. Dynatest. Test Systems Owner'S Manual; Dynatest: Søborg, Denmark, 2015; p. 137.

41. Smith, K.D.; Bruinsma, J.E.; Wade, M.J.; Chatti, K.; Vandenbossche, J.M.; Yu, H.T. Using Falling Weight Deflectometer Data with Mechanistic-Empirical Design and Analysis, Volume I: Final Report; Report No. FHWA-HRT-16-009; Federal Highway Administration: McLean, VA, USA, 2017; Volume I, p. 186.

42. Talvik, O.; Aavik, A. Use of Fwd Deflection Basin Parameters (SCI, BDI, BCI) for Pavement Condition Assessment. Balt. J. Road Bridg. Eng. 2009, 4, 196-202. [CrossRef]

43. Irwin, L.H.; Orr, D.P.; Atkins, D. Falling Weight Deflectometer Calibration Center and Operational Improvements: Redevelopment of The Calibration Protocol and Equipment. Appendix A. Fwd Calibration Protocol; Federal Highway Administration: McLean, VA, USA, 2011; FHWA-HRT-07-040.

44. Harvey, B. Stiffness and damage in masonry bridges. Inst. Civ. Eng. Bridg. Eng. 2012, 165, 127-134. [CrossRef]

45. Wang, H.; Al-Quadi, I.L.; Portas, S.; Coni, M. Three-Dimensional Finite Element Modeling of Instrumented Airport Runway Pavement Responses. In Proceedings of the TRB-Transportation Research Board, 92th Annual Meeting, Washington, DC, USA, 13-17 January 2013; pp. 78-87.

46. Pigozzi, F.; Coni, M.; Portas, S.; Maltinti, F. Implementation of Deflection Bowl Measurements for Structural Evaluations at Network Level of Airport Pavement Management System. In Proceedings of the FAA-Worldwide Airport Technology Transfer Conference-Innovations in Airport Safety and Pavement Technology, Galloway, NJ, USA, 5-7 August 2014; p. 16.

47. Coni, M.; Portas, S.; Maltinti, F.; Pinna, F. Sealing of Paving Stone Joints. Int. J. Pavement Res. Technol. 2018, 11, 813-818. [CrossRef] 